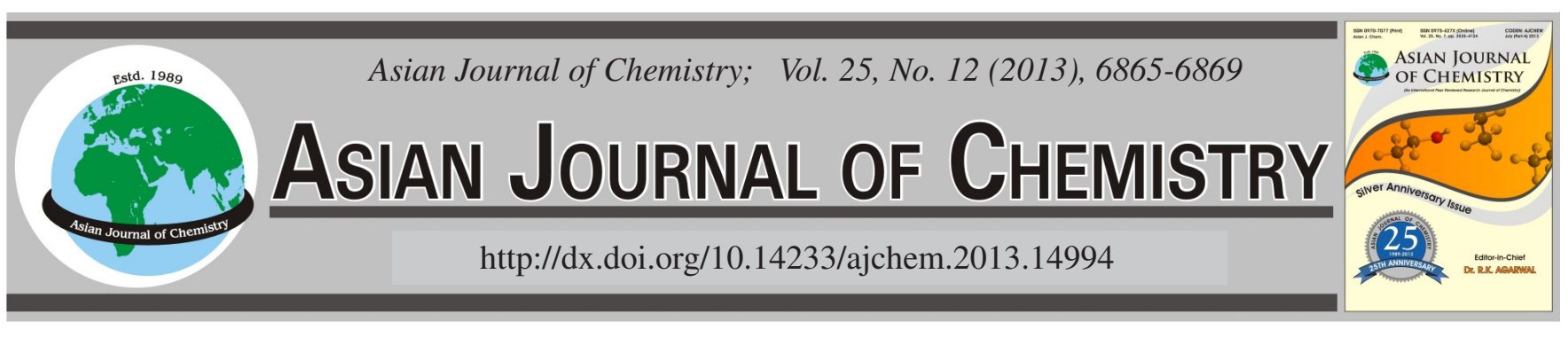

\title{
In vitro Antioxidant and Acetylcholinesterase Inhibitory Activities of the Sesquiterpenes of a Symbiotic Actinomycete Streptomyces sp. from South China Sea
}

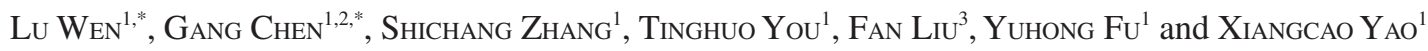

\author{
${ }^{1}$ School of Pharmacy, Guangdong Pharmaceutical University, Guangzhou, Guangdong Province, P.R. China \\ ${ }^{2}$ Guangdong Provincial Key Laboratory of Advanced Drug Delivery, Institute of Materia Medica, Guangdong Pharmaceutical University, \\ Guangzhou, P.R. China \\ ${ }^{3}$ Sericulture and Farm Produce Processing Research Institute, Guangdong Academy of Agricultural Science, Guangzhou, P.R. China
}

*Corresponding authors: E-mail: gywen1@163.com; cg753@126.com

\begin{abstract}
Marine microorganism possesses special metabolic approach to produce compounds with new structures and significant activities. However, reports on secondary metabolites of the symbiotic microorganisms of stony corals are rarely reported up to date. In the course of our search for active constituents from the symbiotic microorganisms of stony corals from the south China sea, five sesquiterpenes were isolated from the actinomycete Streptomyces sp. (ZJG1) and their structures were elucidated by spectrometric methods (NMR, MS and IR, etc). The five sesquiterpenes were analyzed for possible antioxidant and acetylcholinesterase inhibitory activities in three testing systems, including DPPH scavenging method, hemolysis assay and acetylcholinesterase inhibition methods. Compound $\mathbf{3}$ showed good activities in three tests and compound $\mathbf{2}$ exhibited well free radical scavenging and acetylcholinesterase inhibitory activity.
\end{abstract}

Key Words: Symbiotic actinomycete, Stony coral, Antioxidant activity, Acetylcholinesterase inhibitory activity.

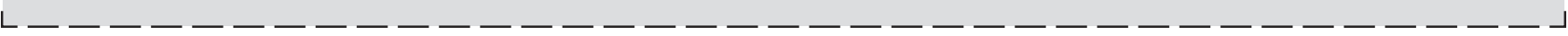

\section{INTRODUCTION}

Actinomycetes are Gram-positive bacteria which have provided a significant source of bioactive secondary metabolites. Since the discovery of actinomycin, cultured bacteria have been a prolific resource for drug discovery, with more than 13000 bioactive metabolites described to date. More than $70 \%$ of these bioactive compounds have been isolated from cultured, primarily terrestrial actinomycetes ${ }^{1}$. However, in recent years, the frequency of discovery of new drug candidates from terrestrial actinomycetes began to decrease and the discovery of new chemical diversity is therefore essential ${ }^{2}$. Research on the metabolites of marine plants and animals began in the early 1970s and to date has yielded large numbers of novel compounds that possess potent biological activities ${ }^{3,4}$. However, bioactive compounds from marine plants and animals are often available only in small amounts, which make it difficult to supply for requirement. Recently, with the dramatic increase in the various diseases, there is an urgent need to identify and develop new lead compounds ${ }^{5-7}$. New resource is needed in order for new medicine candidate materials from natural products to be discovered ${ }^{8}$.

Stony corals have yielded interesting bioactive natural products even though they have been investigated for their secondary metabolites infrequently. And the calcareous body of these animals is assumed to fulfill the defensive role. And there are limited literature data to show that stony corals do produce interesting natural products and more recently evidence of the ecological roles of these metabolites. Of the few secondary metabolites isolated from stony corals, anthraquinoid derivatives ${ }^{9}$, tubastrine ${ }^{10}$, tubastraine ${ }^{11}$, aplysinopsin $^{12}$ and acetylenic derivatives ${ }^{13-15}$ are known. However, reports on the secondary metabolites of symbiotic actinomycetes from stony coral have not been reported up to date. In the course of our search for active constituents from marine microorganisms, significant activity of DPPH scavenging was detected in the crude extract of Streptomyces sp. (ZJG1) from stony coral Diploria strigosa, collected from the south China sea. Further bioactivity-guided fractionation of the extract afforded five sesquiterpenes (1-5). Here we report the isolation, structure elucidation and biological evaluation of the five sesquiterpenes.

\section{EXPERIMENTAL}

General experimental procedures: Melting points were determined with an X-4 micromelting point apparatus (Beijing Tech Instrument Co., LTD.). Optical rotations were measured with a Schmidt \& Haensch Polartronic HH W5 polarimeter. 
IR spectra were measured with a Bruker Vector 22 spectrophotometer. ${ }^{1} \mathrm{H}$ and ${ }^{13} \mathrm{C}$ NMR spectroscopic data were recorded with a Varian Inova $400 \mathrm{MB}$ NMR spectrometer operating at 400 and $100 \mathrm{MHz}$ for ${ }^{1} \mathrm{H}$ and ${ }^{13} \mathrm{C}$, respectively (TMS as internal standard). Mass spectrometric detection was performed on a Thermo Finnigan TSQ Quantum triple quadrupole mass spectrometer (Finnigan MAT, San Jose, CA) equipped with an electrospray ionization (ESI) source. Silica gel (200-300 mesh, Qingdao Haiyang Chemical Co. Ltd) was used for column chromatography (CC). Column chromatography was performed on Sephadex LH-20 (Pharmacia, USA) and RP-18 Lobar (Merck, Darmstadt, Germany). DPPH was purchase from Wako, Japan. Tacrine hydrochloride was purchased from Sigma-Aldrich (St. Louis, MO). True Choline esterase assay kit (50T) was purchased from Nanjing Jiancheng Bioengineering Institute, China.

Fungus isolation and growth conditions: The actinomycete Streptomyces sp. was isolated from stony coral Diploria strigosa from Xuwen, Zhanjiang, south China sea and deposited in the Department of Pharmacy, Guangdong Pharmaceutical University, numbered as ZJG1. The actinomycete was cultured in a Gauze's Medium No. 1 (soluble starch $2 \mathrm{~g}, \mathrm{KNO}_{3} 0.1 \mathrm{~g}$, $\mathrm{K}_{2} \mathrm{HPO}_{4} 0.05 \mathrm{~g}, \mathrm{MgSO}_{4} \cdot 7 \mathrm{H}_{2} \mathrm{O} 0.05 \mathrm{~g}, \mathrm{NaCl} 0.05 \mathrm{~g}$, $\mathrm{FeSO}_{4} \cdot 7 \mathrm{H}_{2} \mathrm{O} 0.001 \mathrm{~g}$, agar $2 \mathrm{~g}$, water $100 \mathrm{~mL}$, pH 7.2-7.4). Starter cultures were maintained on Gauze's Medium No. 1 agar. Plugs of agar supporting mycelia growth were cut and transferred aseptically into a $250 \mathrm{~mL}$ Erlenmeyer flask containing the liquid medium $(100 \mathrm{~mL})$ and incubated at $27^{\circ} \mathrm{C}$ on a rotary shaker for 5 days. The mycelium was aseptically transferred into a $500 \mathrm{~mL}$ Erlenmeyer flask containing the liquid medium $(250 \mathrm{~mL})$. The mycelium was harvested and resuspended to $150 \mathrm{~L}$ liquid Gauze's medium No. 1, incubated at $27^{\circ} \mathrm{C}$ under shaking conditions for 9 days.

Extraction and purification: The total extract (150 L) was evaporated under reduced pressure, partitioned with EtOAc $(250 \mathrm{~mL} \times 5)$ and $\mathrm{H}_{2} \mathrm{O}(250 \mathrm{~mL})$, and given an EtOAc solution, which was concentrated under reduced pressure to give a crude extract $(30.8 \mathrm{~g})$. The crude extract was applied to a silica gel column, using solvent gradient (hexane- $\mathrm{CH}_{2} \mathrm{Cl}_{2}-$ EtOAc-MeOH) to yield seven fractions. Three major bioactive fractions were obtained (Fractions 3, 5 and 6). Fraction 3 was separated by column chromatography (CC) with $\mathrm{CH}_{2} \mathrm{Cl}_{2}$ / EtOAc (90:10, v/v) and yielded compound 1 (25 mg); Fraction 3 as eluted with $\mathrm{CH}_{2} \mathrm{Cl}_{2}$ /EtOAc (85:15) were pooled to afford compound 2 (50 mg); Fraction 5 was subjected to $\mathrm{CC}$ on silica gel $\left(\mathrm{CH}_{2} \mathrm{Cl}_{2} / \mathrm{MeOH}, 85: 15\right)$, which afforded compound $\mathrm{B}$ (100 $\mathrm{mg}$ ); Fraction 6 was further purified by CC on Sephadex (LH20) $\left(\mathrm{MeOH} / \mathrm{H}_{2} \mathrm{O}, 75: 25\right)$, and RP-18 Lobar $\left(\mathrm{MeOH} / \mathrm{H}_{2} \mathrm{O}\right.$, $85: 15)$ yielded compound $\mathbf{4}(10 \mathrm{mg})$ and compound $\mathbf{5}(50 \mathrm{mg})$.

Evaluation of DPPH (2,2-diphenyl-1-picrylhydrazyl) radical scavenging activity: The free radical scavenging activity of the compound was determined by slight modifications of the method described by Sarikurkcu et al. ${ }^{16}$. In its radical form, $\mathrm{DPPH}^{\bullet}$ has an absorption band at $520 \mathrm{~nm}$, which disappears upon reduction by an antiradical compound. 0.5 $\mathrm{mL}$ of various concentrations of the extracts in the methanol was added to $3 \mathrm{~mL}$ of $6 \times 10^{-5} \mathrm{M}$ of a methanol solution of DPPH. This solution was incubated for $0.5 \mathrm{~h}$ in the dark at room temperature. After the incubation, the mixture absorbance was measured at $520 \mathrm{~nm}$. Inhibition activity was calculated in following way:

$$
\mathrm{I}(\%)=\left(\mathrm{A}_{0}-\mathrm{A}_{1}\right) / \mathrm{A}_{0} \times 100,
$$

where $A_{0}$ is the absorbance of the control, $A_{1}$ is the absorbance of the extract/standard. Ethanol $(1 \mathrm{~mL})$ plus sample solution $(10 \mu \mathrm{L})$ was used as a blank. DPPH solution plus ethanol was used as a negative control. The $\mathrm{IC}_{20}$ value is the concentration of testing sample required to scavenge $20 \%$ DPPH free radicals. Vitamin $\mathrm{C}$ was used as positive control. The lower of the $\mathrm{IC}_{20}$ value indicates high antioxidant capacity.

Hemolysis assay ${ }^{17}$ : The membrane-disruptive activity of the compounds was measured using a red blood cell (RBC) hemolysis assay. Red blood cells were harvested by centrifuging whole blood for $4 \mathrm{~min}$. They were washed three times with $100 \mathrm{mM}$ dibasic sodium phosphate and resuspended in the same buffer to yield the initial volume. They were diluted 10 times in the same buffer and $200 \mu \mathrm{L}$ of this suspension was used for each tube. This yields $10^{8} \mathrm{RBCs}$ per tube. Each tube contained $800 \mu \mathrm{L}$ of buffer, $200 \mu \mathrm{L}$ of the RBC suspension and the compounds. Each sample was done in triplicate and was then repeated to verify reproducibility. The tubes were incubated for an hour and a half in a $37^{\circ} \mathrm{C}$ incubator. They were spun for $5 \mathrm{~min}$ at full speed in the microcentifuge. Lysis was determined by measuring the absorbance of the supernatant at $545 \mathrm{~nm}$, reflection the amount of hemoglobin which had been released into the supernatant. Per cent hemolysis was calculated assuming $100 \%$ lysis to be measured by the hemoglobin released by the red blood cells in water; controls of RBCs in buffer with no compounds or in buffer with added streptavidin were also run.

Acetylcholinesterase (AChE) inhibitory activity: $\mathrm{AChE}$ inhibitory activities of compounds $\mathbf{1 - 3}$ were measured by the spectrophotometric method developed by Ellmen ${ }^{18,19}$. Acetylthiocholine iodide was used as substrate in the assay. The reaction mixture contained $1500 \mu \mathrm{L}$ of $(100 \mathrm{mM})$ tris buffer (pH 7.8), $1000 \mu \mathrm{L}$ of DTNB, $200 \mu \mathrm{L}$ (50, 100, 150, $200,250 \mu \mathrm{g} / \mathrm{mL}$ ) of test-compound solution and $200 \mu \mathrm{L}$ of acetyl cholinesterase solution (erythrocytes), which were mixed and incubated for $15 \mathrm{~min}\left(25^{\circ} \mathrm{C}\right)$. The reaction was initiated by the addition of $200 \mu \mathrm{L}$ acetylthiocholine. The hydrolysis of acetylthiocholine was monitored at $412 \mathrm{~nm}$ after $0.5 \mathrm{~h}$. Tacrine was used as positive control. All the reactions were performed in triplicate. The percentage inhibition was calculated as follows ( $\mathrm{E}$ is the activity of the enzyme without test-compound, $\mathrm{S}$ is the activity of enzyme with testcompound):

$$
\text { Inhibition }(\%)=(\mathrm{E}-\mathrm{S}) / \mathrm{E} \times 100 \text {. }
$$

\section{RESULTS AND DISCUSSION}

The crude extract of Streptomyces sp. (ZJG1) was separated into seven fractions by silica gel chromatography, including fractions 1 (0.685 g), 2 (1.642 g), 3 (0.54 g), 4 (9.877 $\mathrm{g}), 5(4.989 \mathrm{~g}), 6(0.417 \mathrm{~g})$ and $7(11.578 \mathrm{~g})$. The free-radicalscavenging activity was tested as bleaching of the stable DPPH (1,1-diphenyl-2-picrylhydrazyl radical) (Fig. 1). Fractions 3, 4 and 6 had good activities and further isolated. 


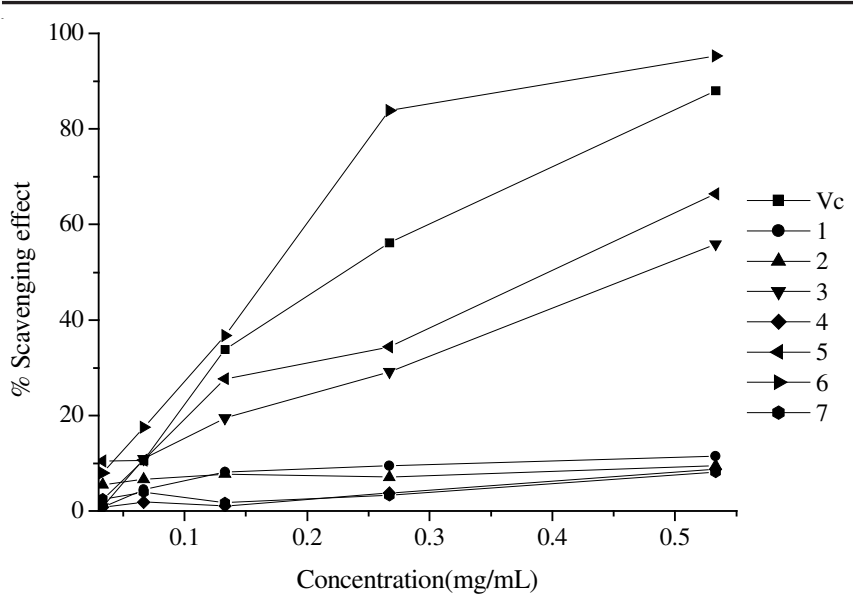

Fig. 1. DPPH scavenging effect of compounds 1-7; $(\mathrm{Vc}=$ vitamin $\mathrm{C})$

Five known compounds were isolated and identified by comparison of their physical and spectroscopic data with those reported in the literature: $\left(1 \mathrm{~S}^{*}, 4 \mathrm{~S}^{*}, 5 \mathrm{R}^{*}, 10 \mathrm{~S}^{*}\right)$-guai-6-en10-ol (1), guai-2-en-10a-ol (2), (-)-2,3,3a,4,5,6-hexahydro-1,4dimethylazulen-4-ol (3), pogostol (4) and methoxycolorenone (5) (Fig. 2). The structures of these compounds were given in the supporting information at below.
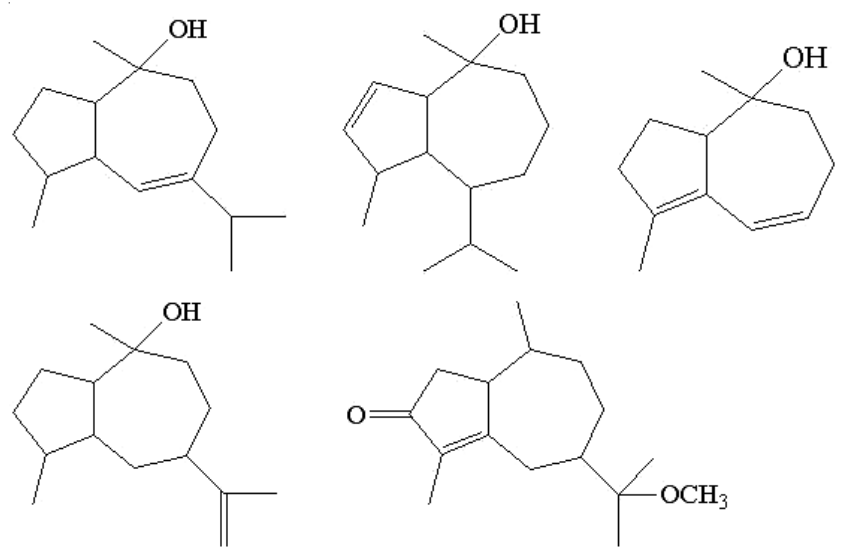

Fig. 2. Structures of compounds $\mathbf{1 - 5}$

Sesquiterpene 1 was obtained as a colourless oil, the ESIMS showed the molecular ion peaks at $245[\mathrm{M}+\mathrm{Na}]^{+}$in the positive mode. The ${ }^{13} \mathrm{C}$ NMR spectral data indicated the presence of four methyls at $\delta 21.4,21.1,21.1,14.1$, four methylenes at $\delta 42.6,32.8,25.8,23.8$, four methines at $\delta 51.0$, $44.2,38.7,36.9$, one olefinic bond at $\delta 148.2$ and 124.8 , one hydroxylated quatermary carbon at $\delta 72.0$. The ${ }^{1} \mathrm{H}$ NMR spectrum demonstrated that the individual signals assigned for the same positions moved closer together, which confirmed our hypothesis. With the literature, the structure was confirmed as $\left(1 \mathrm{~S}^{*}, 4 \mathrm{~S}^{*}, 5 \mathrm{R}^{*}, 10 \mathrm{~S}^{*}\right)$-guai-6-en-10-ol (1). The compound has been isolated from the leaves of Guarea guidonia ${ }^{20}$.

Guaiane 2 was isolated as yellowish oil. The IR absorption band at $2934 \mathrm{~cm}^{-1}$ was due to - $\mathrm{CH}$ stretching vibrations. The - $\mathrm{OH}$ group in the skeleton exhibited free $-\mathrm{OH}$ stretching vibrations near $3030 \mathrm{~cm}^{-1}$. Its (+)ESI-MS exhibited a molecular ion peak at $\mathrm{m} / \mathrm{z} 245[\mathrm{M}+\mathrm{Na}]^{+}$, which in combination with its ${ }^{1} \mathrm{H}$ and ${ }^{13} \mathrm{C}$ NMR data indicated the elemental composition of $\mathrm{C}_{15} \mathrm{H}_{26} \mathrm{O}$, a guaiane sesquiterpene with three degrees of unsaturation. The ${ }^{1} \mathrm{H}$ NMR showed four methyl signals at $\delta$
$1.02,1.03,2.22$ and 1.16 , due to $12-\mathrm{CH}_{3}, 13-\mathrm{CH}_{3}, 14-\mathrm{CH}_{3}$, $15-\mathrm{CH}_{3}$, methylenes at $\mathrm{C}-7(\delta 1.19,1.32), \mathrm{C}-8(\delta 1.20,1.41)$, C-9 $(\delta 1.26,1.57)$ and methine multiplets. The ${ }^{13} \mathrm{C}$ NMR spectrum of $\mathbf{2}$ in combination with DEPT experiments indicated the occurrence of 15 carbon atoms in the molecule, including two olefinic carbons at $\delta 132.5$ and 130.9 and four methyl groups. With the literature, the observations confirmed the structure as guai-2-en-10a-ol (2) ${ }^{21}$.

Compound $\mathbf{3}$, a trinor-sesquiterpene alcohol, occurred as essential oil. Compound $\mathbf{3}$ exhibited a molecular ion signal at $\mathrm{m} / \mathrm{z} 178$ corresponding to the molecular formula $\mathrm{C}_{12} \mathrm{H}_{18} \mathrm{O}$. The ${ }^{1} \mathrm{H}$ NMR spectrum $\left(\mathrm{C}_{6} \mathrm{D}_{6}\right)$ of $\mathbf{3}$ showed signals of two singlets for methyl groups at $\delta 0.96$ and 1.53 , respectively. The deshielded signals at $\delta 5.56$ and 6.48 were assigned to the vinylic protons at $\mathrm{H}-7$ and $\mathrm{H}-8$, respectively. The ${ }^{13} \mathrm{C}$ NMR showed the carbon signal at $\delta 73.4$ was assigned to the tertiary hydroxyl group. With the literature, the structure was confirmed (-)-2,3,3a,4,5,6-hexahydro-1,4-dimethylazulen-4-ol (3) ${ }^{22}$.

The structure of compound $\mathbf{4}$ was unambiguously assigned as pogostol by comparison of its spectroscopic data with the literature. Compound 4 gave a $[\mathrm{M}+1]^{+}$peak at $\mathrm{m} / \mathrm{z} 223$, which corresponded to a molecular formula of $\mathrm{C}_{15} \mathrm{H}_{26} \mathrm{O}$ and three sites of unsaturation and (+)ESI-MS of compound $\mathbf{4}$ also gave an $(\mathrm{M}-18)^{+}$at $\mathrm{m} / \mathrm{z} 204$ that showed a loss of $\mathrm{H}_{2} \mathrm{O}$. The ${ }^{13} \mathrm{C}$ NMR spectrum showed two olefinic carbons typical of an exocyclic methylene double bond, one oxygen-bearing quaternary carbon, four methines, five methylenes and three methyl groups. One of the methyl groups was a doublet in the ${ }^{1} \mathrm{H}$ NMR spectrum and the other two were attached to quaternary centers. These data required a bicyclic structure for compound 4. The ${ }^{1} \mathrm{H}$ NMR and IR spectral data for this compound were identical to those of pogostol, reported from the oil of the patchouli plan, Pogostemon cablin ${ }^{23}$ and the ${ }^{13} \mathrm{C}$ NMR spectral data were reported from the Pithomyces sp. isolated from the Pit Lake ${ }^{24}$.

Compound $\mathbf{5}$ showed a protonated molecular ion $[\mathrm{M}+\mathrm{H}]^{+}$ at $\mathrm{m} / \mathrm{z} 251$, which was compatible with the molecular composition of $\mathrm{C}_{16} \mathrm{H}_{26} \mathrm{O}_{2}$. The ${ }^{1} \mathrm{H}$ NMR spectrum showed an additional singlet signal at $\delta 3.20$ corresponding to $-\mathrm{OCH}_{3}$. The ${ }^{13} \mathrm{C}$ NMR spectrum showed that a methoxyl signal at $\delta 77.4$, which was positioned at C-11 from the 4- to 5-ppm highfield shifts of C-7, C-12 and C-13. With the literature, the observations confirm the structure of the compound $\mathbf{5}$ as methoxycolorenone $^{25}$.

All sesquiterpenes isolated were analyzed for possible antioxidant and acetylcholinesterase inhibitory activities in three test systems. For the screening and evaluation of antioxidant activity of the five compounds, a DPPH assay was adopted ${ }^{16}$ (Fig. 3). In the DPPH assay system, the free radical scavenging activity of the tested sample was expressed as $\mathrm{IC}_{20}$. Compound $\mathbf{3}$ showed the most free redical scavenging activity $(0.72 \mathrm{mg} / \mathrm{mL})$ in the five tested compounds. Compound 2 $(0.38 \mathrm{mg} / \mathrm{mL})$ showed a moderate activity than vitamin C (0.94 $\mathrm{mg} / \mathrm{mL})$.

The five sesquiterpenes efficiently induce red blood cell (RBC) hemolysis. This serves as a model to test the ability of the compound, with disrupting the lipid bilayers of RBC membranes ${ }^{17}$. As a result, compound $\mathbf{3}$ showed the best values than the other compounds (Fig. 4). 


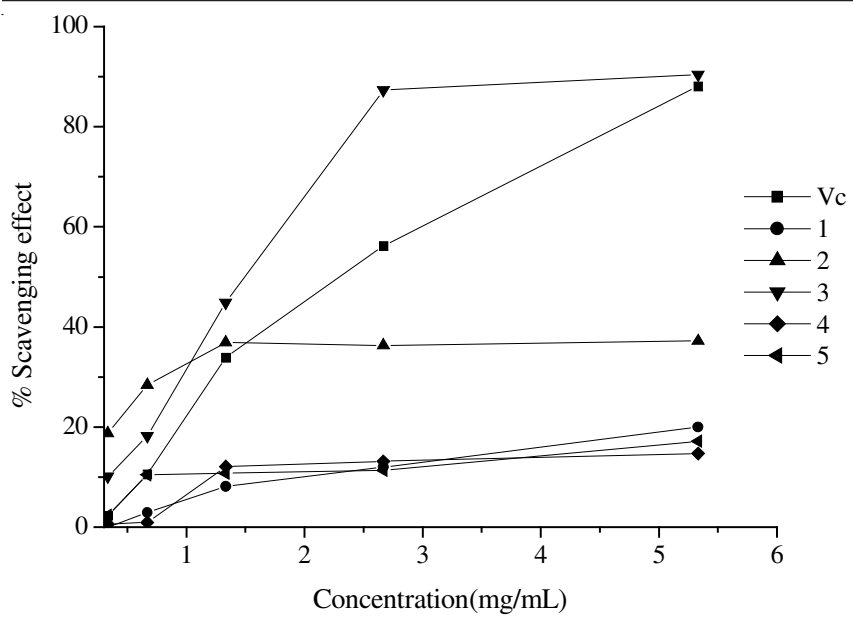

Fig. 3. DPPH scavenging activity of compounds $\mathbf{1 - 5}$; $(\mathrm{Vc}=$ vitamin $\mathrm{C})$

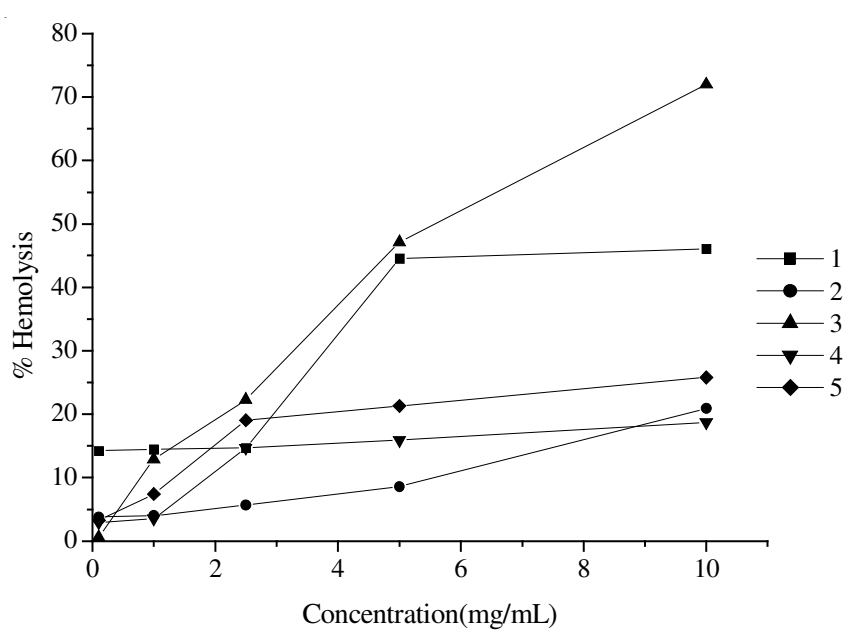

Fig. 4 Hemolytic activity for the compounds $\mathbf{1 - 5}$

AChE inhibitors are used in a major treatment for symptoms of the early stages of Alzheimer's disease ${ }^{18}$. The five sesquiterpenes were tested for AChE inhibitory activity. Compounds $\mathbf{2}$ and $\mathbf{3}$ exhibited strong inhibition of AChE in vitro, the inhibition ratios of compounds $\mathbf{2}$ and $\mathbf{3}$ were $82.90 \%$ and $80.17 \%$, respectively, with activities similar to that of Tacrine $(89.72 \%)$, with $1 \mathrm{U} / \mathrm{mL}$ of the activity of myocardial enzymes.

$\left(1 S^{*}, 4 S^{*}, 5 R *, 10 S^{*}\right)$-guai-6-en-10-ol (1): Colourless oil, $[\alpha]_{25}{ }^{\mathrm{D}}-21.5^{\circ}(\mathrm{c} 1, \mathrm{MeOH}) ; \mathrm{IR}\left(\mathrm{KBr}, v_{\max }, \mathrm{cm}^{-1}\right): 3434,2950$, 2870, 1643, 1487, 1376, 1150, 890; ESI-MS (positive) m/z $245[\mathrm{M}+\mathrm{Na}]^{+}, 204,161,121,55 .{ }^{1} \mathrm{H}$ NMR $\left(\mathrm{CDCl}_{3}, 400 \mathrm{MHz}\right)$ : $\delta 1.95$ (1H, m, H-1), 1.60 (2H, m, H-2, H-3), 1.74 (2H, m, H2, H-9), 1.32 (2H, m, H-3, H-14), 2.23 (2H, m, H-4, H-5), $5.20(1 \mathrm{H}, \mathrm{d}, 4.0 \mathrm{~Hz}, \mathrm{H}-6), 1.83(1 \mathrm{H}, \mathrm{m}, \mathrm{H}-8), 1.96(1 \mathrm{H}, \mathrm{m}, \mathrm{H}-$ 8), 1.43 (1H, m, H-9), 2.20 (1H, m, H-11), 0.90 (3H, d, 7.0 Hz, H-12), 0.90 (3H, d, 7.0 Hz, H-13), 0.83 (3H, d, 7.5 Hz, H15). ${ }^{13} \mathrm{C}$ NMR $\left(\mathrm{CDCl}_{3}, 100 \mathrm{MHz}\right): \delta 51.0(\mathrm{C}-1), 23.8(\mathrm{C}-2)$, 32.8 (C-3), 36.9 (C-4), 44.2 (C-5), 124.8 (C-6), 148.2 (C-7), 25.8 (C-8), 42.6 (C-9), 72.0 (C-10), 38.7 (C-11), 21.1 (C-12), 21.1 (C-13), 21.4 (C-14), 14.1 (C-15). ${ }^{1} \mathrm{H}$ and ${ }^{13} \mathrm{C}$ NMR data were in agreement with the reported data for $\left(1 \mathrm{~S}^{*}, 4 \mathrm{~S}^{*}, 5 \mathrm{R}^{*}\right.$, $\left.10 \mathrm{~S}^{*}\right)$-guai-6-en-10-ol ${ }^{20}$.

Guai-2-en-10 $\alpha$-ol (2): Yellowish oil, IR $\left(\mathrm{KBr}, \mathrm{v}_{\max }, \mathrm{cm}^{-1}\right)$ : 3030, 2934, 1416, 1055, 810; ESI-MS (positive) m/z 245 $[\mathrm{M}+\mathrm{Na}]^{+}, 208,180,124,96,56 .{ }^{1} \mathrm{H} \mathrm{NMR}\left(\mathrm{CDCl}_{3}, 400 \mathrm{MHz}\right)$ : $\delta 2.13(1 \mathrm{H}, \mathrm{m}, \mathrm{H}-1), 5.56(1 \mathrm{H}, \mathrm{m}, \mathrm{H}-2), 5.35$ (1H, m, H-3), 3.15 (1H, m, H-4), 1.96 (1H, m, H-5), 1.55 (1H, d, $7.0 \mathrm{~Hz}, \mathrm{H}-$ 6), 1.32 (1H, m, H-7a), 1.19 (1H, t, 2.0, $1.5 \mathrm{~Hz}, \mathrm{H}-7 \mathrm{~b}), 1.40$ (1H, t, $1.5 \mathrm{~Hz}, \mathrm{H}-8 \mathrm{a}), 1.20$ (1H, m, H-8b), 1.57 (1H, m, H-9a), $1.26(3 \mathrm{H}, \mathrm{t}, 5.0,2.0 \mathrm{~Hz}, \mathrm{H}-9 \mathrm{~b}), 3.08$ (1H, bs, OH-10), 1.12 (1H, m, H-11), 1.02 (3H, d, 6.5 Hz, H-12), 1.03 (3H, d, 6.5 $\mathrm{Hz}, \mathrm{H}-13), 2.22$ (3H, s, H-14), $1.16(3 \mathrm{H}, \mathrm{d}, 7.0 \mathrm{~Hz}, \mathrm{H}-15) .{ }^{13} \mathrm{C}$ $\mathrm{NMR}\left(\mathrm{CDCl}_{3}, 100 \mathrm{MHz}\right): \delta 48.8$ (C-1), 130.9 (C-2), 132.5 (C-3), 44.2 (C-4), 36.8 (C-5), 40.1 (C-6), 30.4 (C-7), 18.7 (C8), 38.8 (C-9), 74.1 (C-10), 25.8 (C-11), 33.8 (C-12), 21.1 (C13), 22.7 (C-14), 19.6 (C-15). ${ }^{1} \mathrm{H}$ and ${ }^{13} \mathrm{C}$ NMR data were in agreement with the reported data for guai-2-en-10a-ol ${ }^{21}$.

(-)-2,3,3a,4,5,6-Hexahydro-1, 4-dimethylazulen-4-ol (3): Colourless oil, ESI-MS (positive) m/z $178\left[\mathrm{M}^{+}, 160,131\right.$, 117, 91, 77, 65, 51. ${ }^{1} \mathrm{H}$ NMR $\left(\mathrm{C}_{6} \mathrm{D}_{6}, 400 \mathrm{MHz}\right): \delta 2.10(1 \mathrm{H}$, m, H-2a), 2.05 (1H, m, H-2b), 1.80 (1H, m, H-3a), 1.55 (1H, m, H-3b), 1.79 (1H, m, H-5), 2.05 (1H, m, H-6a), 1.96 (1H, m, H-6b), 5.56 (1H, m, H-7), 6.48 (1H, d, $12.0 \mathrm{~Hz}, \mathrm{H}-8), 3.11$ (1H, m, H-10), 1.53 (1H, br s, H-11), $0.96(3 \mathrm{H}, \mathrm{s}, \mathrm{H}-12) .{ }^{13} \mathrm{C}$ NMR $\left(\mathrm{C}_{6} \mathrm{D}_{6}, 100 \mathrm{MHz}\right): \delta 139.7$ (C-1), 38.0 (C-2), 23.9 (C3), 73.4 (C-4), 45.1 (C-5), 25.5 (C-6), 129.3 (C-7), 127.4 (C8), 130.7 (C-9), 60.6 (C-10), 16.9 (C-11), 21.3 (C-12). ${ }^{1} \mathrm{H}$ and ${ }^{13} \mathrm{C}$ NMR data were in agreement with the reported data for (-)-2,3,3a,4,5,6-hexahydro-1,4-dimethylazulen-4-ol ${ }^{22}$.

Pogostol (4): Colourless oil, $[\alpha]_{20}{ }^{\mathrm{D}}-18.5(\mathrm{MeOH}, \mathrm{c} 1.0)$; IR $\left(\mathrm{KBr}, v_{\max }, \mathrm{cm}^{-1}\right): 3423,2934,2870,1645,1487,1384$, 886; ESI-MS (positive) m/z $223[\mathrm{M}+\mathrm{H}]^{+}, 205\left[\mathrm{M}+\mathrm{H}-\mathrm{H}_{2} \mathrm{O}\right]^{+}$. ${ }^{1} \mathrm{H} \mathrm{NMR}\left(\mathrm{CDCl}_{3}, 400 \mathrm{MHz}\right): \delta 2.12(1 \mathrm{H}, \mathrm{m}, \mathrm{H}-1), 1.65(5 \mathrm{H}$, m, H-2, H-3, H-12), 1.45 (2H, m, H-2, H-9), 1.22 (2H, m, H3, H-6), 2.17 (2H, m, H-4, H-5), 1.38 (2H, m, H-6, H-8), 2.20 (m, H-7), 1.74 (m, H-8), 1.80 (m, H-9), 4.74 (br s, H-13), 4.64 (br s, H-13), 1.10 (3H, s, H-14), 0.88 (3H, d, $6.8 \mathrm{~Hz}, \mathrm{H}-15)$; ${ }^{13} \mathrm{C} \mathrm{NMR}\left(\mathrm{CDCl}_{3}, 100 \mathrm{MHz}\right): \delta 56.3(\mathrm{C}-1), 26.0(\mathrm{C}-2), 31.3$ (C-3), 38.8 (C-4), 45.6 (C-5), 28.4 (2C, C-8, C-6), 46.2 (C-7), 35.3 (C-9), 73.5 (C-10), 150.1 (C-11), 17.9 (C-12), 109.7 (C13), 29.8 (C-14), $15.4(\mathrm{C}-15) .{ }^{1} \mathrm{H}$ and ${ }^{13} \mathrm{C}$ NMR data were in agreement with the reported data for pogostol ${ }^{23,24}$.

Methoxycolorenone (5): Colourless oil, $[\alpha]_{20}{ }^{\mathrm{D}}+17.8^{\circ}$ $\left(\mathrm{CHCl}_{3}, \mathrm{c} 1.0\right.$ ); ESI-MS (positive) m/z $251[\mathrm{M}+\mathrm{H}]^{+}, 218,178$, 73. ${ }^{1} \mathrm{H}$ NMR (acetone- $\left.d_{6}, 400 \mathrm{MHz}\right): \delta 3.21(1 \mathrm{H}, \mathrm{brm}, \mathrm{H}-1$ ), 2.44 (1H, ddd, 18.5, 6.5, $1.0 \mathrm{~Hz}, \mathrm{H}-2 \mathrm{a}), 1.99$ (1H, ddd, 18.5, 1.5, $1.0 \mathrm{~Hz}, \mathrm{H}-2 \mathrm{~b}), 2.92$ (1H, dm, H-6a), 2.30 (1H, ddm, 19.5, $12.0 \mathrm{~Hz}, \mathrm{H}-6 \mathrm{~b}), 1.89$ (1H, m, H-7), 2.03 (1H, m, H-8a), 1.27 (1H, m, H-8b), 1.80 (1H, dddd, 14.0, 4.5, 3.5, 3.5Hz, H-9a), 1.64(1H, dddd, 14.0, 13.5, 3.5, $3.5 \mathrm{~Hz}, \mathrm{H}-9 \mathrm{~b}), 2.17(1 \mathrm{H}, \mathrm{m}$, H-10), 1.16 (3H, s, H-12), 1.14 (3H, s, H-13), 0.86 (3H, d, 7.5 $\mathrm{Hz}, \mathrm{H}-14), 1.61$ (3H, ddd, 1.5, 1.5, 1.5 Hz, H-15), 3.20 (3H, s, $\mathrm{H}-16) .{ }^{13} \mathrm{C}$ NMR (acetone- $d_{6}, 100 \mathrm{MHz}$ ): $\delta 46.3$ (C-1), 41.7 (C-2), 207.0 (C-3), 136.1 (C-4), 180.4 (C-5), 34.2 (C-6), 45.0 (C-7), 27.3 (C-8), 37.8 (C-9), 36.3 (C-10), 77.4 (C-11), 22.5 (C-12), 22.8 (C-13), 14.2 (C-14), 10.8 (C-15), 49.6 (C-16). ${ }^{1} \mathrm{H}$ and ${ }^{13} \mathrm{C}$ NMR data were in agreement with the reported data for methoxycolorenone ${ }^{25}$.

\section{Conclusion}

Symbiotic actinomycete living with animals have been implicated in the synthesis of defensive and other natural products of importance to drug discovery. As a new resource, studies of symbiont-derived natural products have focused on 
coral in our research. The result showed that coral symbiotic actinomycete was a rich source of novel and/or biologically active metabolites. In addition to investigating this basic question, we think that exploration of an untapped actinomycete could lead to the discovery of new bioactive natural products.

\section{ACKNOWLEDGEMENTS}

The authors acknowledged the financial grant from the National Nature Science Foundation of China (No. 81274097), the Project for Zhujiang Science and Technology New Star of Guangzhou, the Science and Technology Planning Project of Guangdong Province (No. 2012B031800227) and the Project of Department of Education of Guangdong Province (2012KJCX0069).

\section{REFERENCES}

1. J. Berdy, J. Antibiot., 58, 1 (2005).

2. J.W. Li and J.C. Vederas, Science, 325, 161 (2009).

3. D.J. Faulkner, Nat. Prod. Rep., 17, 1 (2000).

4. J.W. Blunt, B.R. Copp, W.P. Hu, M.H. Munro, P.T. Northcote and M.R. Prinsep, Nat. Prod. Rep., 25, 35 (2008).

5. B. Haefner, Drug Discovery Today, 8, 536 (2003).

6. M.S. Butler, Nat. Prod. Rep., 22, 162 (2005).

7. M.S. Butler, Nat. Prod. Rep., 25, 475 (2008).

8. M. Takagi and K. Shin-ya, J. Antibiot., 64, 699 (2011).

9. R. Sanduja, M. Alarm and G.M. Wellington, J. Chem. Res. Synop., 5, 450 (1986).
10. R. Sakai and T. Higa, Chem. Lett., 127 (1987).

11. M. Alam, R. Sanduja and G.M. Wellington, Heterocycles, 27, 719 (1988).

12. N. Fusetani, M. Asano, S. Matsunaga and K. Hashimoto, Comp. Biochem. Physiol., 85B, 845 (1986).

13. B.H. Bae, K.S. Im, W.C. Choi, J. Hong, C.O Lee, J.S. Choi, B.W. Son, J.I. Song and J.H. Jung, J. Nat. Prod., 63, 1511 (2000).

14. N. Alam, B.H. Bae, J. Hong, C.O. Lee, K.S. Im and J.H. Jung, J. Nat. Prod., 64, 1059 (2001)

15. N. Alam, J. Hong, C. O. Lee, K.S. Im, B.W. Son, J.S. Choi, W.C. Choi and J.H. Jung, J. Nat. Prod., 64, 956 (2001).

16. C. Sarikurkcu, B. Tepe, D. Daferera, M. Polissiou and M. Harmandar, Bioresour. Technol., 99, 4239 (2008).

17. C.A. Lackey, N. Murthy, O.W. Press, D.A. Tirrell, A.S. Hoffman, and P.S. Stayton, Bioconjugate Chem., 10, 401 (1999).

18. I.K. Rhee, N. Appels, B. Hofte, B. Karabatak, C. Erkelens, L.M. Stark, L.A. Flippin and R. Verpoorte, Biol. Pharm. Bull., 27, 1804 (2004).

19. G.L. Ellman, K.D. Courtney, V. Andres Jr. and R.M. Feather-Stone, Biochem. Pharmacol., 7, 88 (1961).

20. C.B. Brochini, C.V. Núñez, I.C. Moreira and N.F. Roque, Quím. Nova, 22, 37 (1999).

21. K. Chakraborty, A.P. Lipton, P. Paulraj and R.D. Chakraborty, Eur. J. Med. Chem., 45, 2237 (2010).

22. A.M. Adio and W.A. König, Tetrahedron: Asymm., 18, 1693 (2007).

23. Y. Yang, K. Kinoshita, K. Koyama, K. Takahashi, T. Tai, Y. Nunoura and K. Watanabe, Phytomedicine, 6, 89 (1999).

24. A.A. Stierle, D.B. Stierle, E. Goldstein, K. Parker, T. Bugni, C. Baarson, J. Gress and D. Blake, J. Nat. Prod., 66, 1097 (2003).

25. D. Handayani, R.A. Edrada, P. Proksch, V. Wray, L. Witte, R.W. van Soest, A. Kunzmann and Soedarsono, J. Nat. Prod., 60, 1313 (1997). 